\title{
Measuring the impact of e-learning on increasing organization quality of services: Case study of medical university in Ilam
}

\author{
Meysam Mirabizadeh ${ }^{*}$ and Sajad Gheitasi
}

Department Industrial Engineering, Islamic Azad University, Ilam Branch, Iran

\begin{tabular}{|c|c|}
\hline ARTICLE I N F O & A B S T R A C T \\
\hline $\begin{array}{l}\text { Article history: } \\
\text { Received July 10, } 2011 \\
\text { Received in Revised form } \\
\text { October, 3, } 2011 \\
\text { Accepted 10 January } 2012 \\
\text { Available online } \\
\text { 19 January } 2012 \\
\text { Keywords: } \\
\text { E-learning } \\
\text { Organization quality of services } \\
\text { Information technology }\end{array}$ & $\begin{array}{l}\text { Information technology has made tremendous changes on ways people learn and communicate. } \\
\text { People could go through internet to have an access to many knowledge based websites such as } \\
\text { Wikipedia to learn or they may participate in e-learning programs offered by different well } \\
\text { known universities in the world without bothering about the borders between countries. E- } \\
\text { learning has proven as a cost efficient method especially for courses where there is no need to } \\
\text { offer physical lab courses. It can literally eliminate different cost items involved with traditional } \\
\text { learning such as transportation or the cost of leaving a job to learn more. The proposed study of } \\
\text { this paper attempts to understand whether e-learning has any positive impact on quality } \\
\text { improvement in an organization. The proposed study of this paper performs a survey on } 525 \\
\text { people who work in medical school of Ilam. We have chosen a sample of } 223 \text { people and } \\
\text { designed a questionnaire based on Likert scale. The results indicate that e-learning has positive } \\
\text { relationship with quality improvement in an organization. }\end{array}$ \\
\hline
\end{tabular}

(C) 2012 Growing Science Ltd. All rights reserved.

\section{Introduction}

For many years, people used to educate themselves by attending well-known schools through traveling to different countries. Traveling and enquiring the necessary document such as visa have been major concerns for many people who plan to attend educational programs in other countries. In such circumstances, e-learning plays an important role on removing such barriers. E-learning has other advantages such as saving people's time by attending a program with leaving job. In fact, the purpose of many e-learning programs is to ask students to take part in educational programs mostly after work-hour or during the weekend. These programs could increase graduated people to contribute more on their work and there are various studies on that.

Abdelaziz et al. (2011) proposed a method for assessment of e-learning program versus traditional learning programs for undergraduate nursing students in a faculty of nursing. They reported statistical results in terms of knowledge gained, practice, attitudes, and opinions between traditional lectures and e-learning. They indicated lack of computer skills of students affected their abilities to * Corresponding author. Tel: +989188425250

E-mail addresses: meysammirabizadeh@yahoo.com (M. Mirabizadeh) 
communicate efficiently with the instructor and failed to take part in different online communication methods. The people who attended the study were satisfied with the e-learning program as a teaching method, but they were interested in e-learning program only when they had computer and Internet at home. The study suggested to implement a "blended learning environment" by integrating the strengths of both e-learning and lecture into nursing education for efficient and effective instruction and overcome the deficiency of limited skills and resources.

Krause et al. (2009) investigated the effects of cooperative learning and feedback on e-learning by 137 university students who participated in a survey. They reported cooperative learning was able to enhance perceived performance, competence and collective efficacy could influence on self-efficacy. Payne et al. (2009) studied whether an e-learning method, which implements constructivist techniques could be used to train employees in highly specialized skills using expert individuals and extensive prolonged training. The approach used the development of e-learning facilities including simulations and interactivity.

The survey performed some experimental testing in a case study workplace environment by gathering both quantitative and qualitative information to assess the effectiveness of the technique. The survey indicated that the e-learning strategy could improve the skills of the inexperienced operator, substantially. They also claimed that such programs could be implemented as a work based training aid for training employees in complex skilled tasks in the workplace and explained that the e-learning could be implemented outside the traditional learning environment to train unskilled employees for practical tasks, which conventionally would involve expensive instruction. Payne et al. (2009) also explained that simulations was a powerful technique in the design of successful e-learning packages in preparing learners for real-world applications.

Cegarra-Navarro et al. (2007) investigated the relative importance of the four learning techniques introduced in the literature on four various levels of e-business including null, external, relational and internal by a survey of 130 SMEs in the Spanish telecommunications sector. The survey was performed by using a multinomial logistic model, validated by factor analysis. The results explained that to use e-business, firms are required to provide the acquisition, interpretation and storage of knowledge as prior steps. The findings further recommended that knowledge acquisition was necessary to progress from relational level to internal level.

Bhuasiri et al. (2012) performed a survey to find critical success factor (CSF) for e-learning in developing countries. The study identified CSFs, which impact the acceptance of e-learning systems in developing countries. The study determined multiple factors, which impact the success of elearning systems from the literature and compared the relative importance between two stakeholder groups in developing countries including ICT experts and faculty. The study gathered 76 usable responses based on Delphi method and Analytic Hierarchy Process (AHP) approach and reported 6 dimensions and $20 \mathrm{CSF}$ for e-learning systems in developing countries. Findings explained the importance of curriculum design for learning performance. Technology awareness, motivation, and changing learners' behavior are prerequisites for successful e-learning implementations. They also provided different suggestions to help the implementation of e-learning systems for developing countries. AbuSneineh and Zairi (2010) provided an assessment framework for e-Learning effectiveness in the Arab World.

Keramati et al. (2011) investigated the role of e-learning readiness on the performance of e-leaning programs through an empirical study. They proposed a conceptual framework for the assessment of the impact of readiness factors on the relationship between e-learning factors and its outcomes. Readiness elements were divided into three main groups including technical, organizational and social. Their results indicated that organizational readiness factors were the most important factors on e-learning outcomes. In addition, teachers' motivation and training was the most important element in e-learning. 
Ćukušić et al. (2010) performed an empirical study on e-learning process management and the elearning performance. The study used a sample of 14 European schools participating in an EU-funded project. They reported the existence of a relationship between planning and controlling of the elearning process and the learning outcomes. They also reported that the model and its practical implications could be implemented by institutions engaged in e-learning, or as a process model for elearning activities.

The proposed study of this paper attempts to provide an empirical study to measure the relationship between e-learning programs and the quality of organization. The study of this paper is implemented among the people who took part in such programs and work for this medical school.

\section{The proposed study}

In this survey, we decided to do the survey among all people who were involved with e-learning in the medical school of Ilam. The population of our survey covers 525 people and the maximum error in our computation does not have to exceed five percent. The questions are in qualitative perspective from very low to very high in Likert scale (Likert, 1932). We also assigned weight values of one to five for different scales from very low to very high, respectively. Finally we assume the population follows a normal distribution. Therefore we could use the following formula to calculate the minimum number of sample size,

$n=\frac{N \times z_{\alpha / 2}^{2} \times p \times q}{\varepsilon^{2} \times(N-1)+z_{\alpha / 2}^{2} \times p \times q}$,

where $N$ is the population size, $p=1-q$ represents the yes/no categories, $z_{\alpha / 2}$ is CDF of normal distribution and finally $\varepsilon$ is the error term. Since we have $p=0.5, z_{\alpha / 2}=1.96$ and $N=525$, the number of sample size is calculated as $n=223$. Table 2 shows the educational levels of the people who participated in our survey. We first selected a sample 30 people and performed the survey and calculated Conbach Alpha, which yields 0.933 and this is well above the minimum level of 0.70. Therefore, we can conclude that the questionnaire maintains a good and reliable form of survey. Fig. 1 shows details of our proposed model.

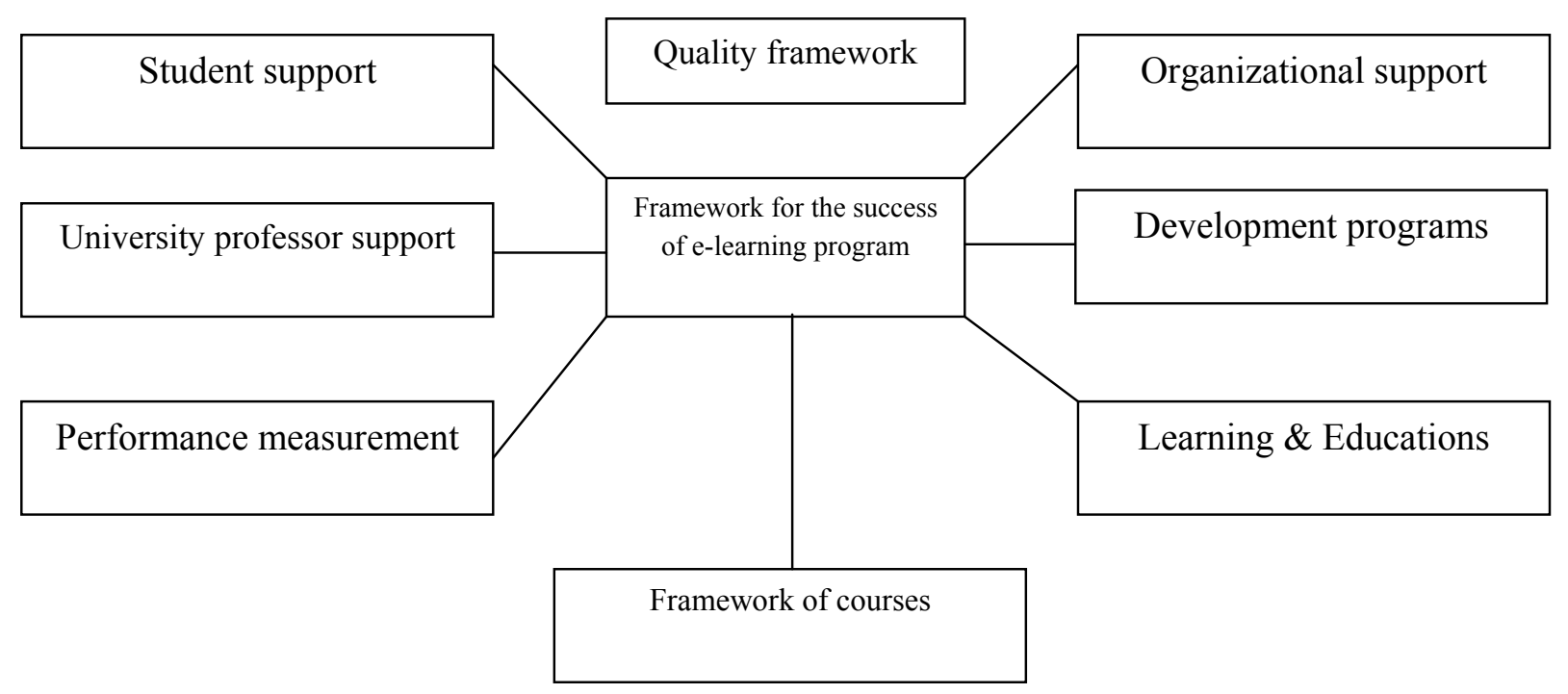

Fig. 1. The proposed framework of the study 
The main hypothesis associated with the proposed study of this paper is as follows,

H1: The implementation of the proposed framework could improve the quality of organization.

There are seven sub-hypotheses associated with the proposed study of this paper which are as follows,

1. Supporting e-learning programs by organization has positive influence on quality of organization.

2. The existence of development program for e-learning has positive influence on quality of organization.

3. Using of Learning \& Educations benchmark has positive influence on quality of organization

4. Using of Framework of courses benchmark has positive influence on quality of organization.

5. Using a supportive team for students in e-learning has positive influence on quality of organization.

6. Using a supportive team for instructors in e-learning has positive influence on quality of organization.

7. Using of Performance measurement benchmark has positive influence on quality of organization.

\section{The results}

In this section, we present details of our finding on this survey, which were analyzed using SPSS software package. Note that for all hypotheses we have considered the following general test,

$\begin{cases}H_{0} & \mu \leq 3 \\ H_{1} & \mu>3\end{cases}$

Table 1 shows details of our findings,

\section{Table 1}

The results of the survey all hypotheses

\begin{tabular}{llllllll}
\hline $\mathrm{H}$ & Independent variable & $\begin{array}{l}\text { Dependent } \\
\text { variable }\end{array}$ & $\begin{array}{l}\mathrm{t}- \\
\text { student }\end{array}$ & Sig. & df & $\begin{array}{l}95 \% \text { confidence } \\
\text { interval }\end{array}$ & Result \\
\hline 1 & Organizational support & Improving quality & 10.238 & 0.000 & 209 & $0.2134-0.3154$ & Confirmed \\
2 & Development programs & Improving quality & 3.535 & 0.001 & 209 & $0.0458-0.1613$ & Confirmed \\
3 & Learning \& Educations & Improving quality & 13.860 & 0.000 & 209 & $0.4789-0.6377$ & Confirmed \\
4 & Framework of courses & Improving quality & 16.860 & 0.000 & 209 & $0.5025-0.6356$ & Confirmed \\
5 & Student support & Improving quality & 10.319 & 0.000 & 209 & $0.3020-0.4447$ & Confirmed \\
6 & University professor support & Improving quality & 13.238 & 0.000 & 209 & $0.4012-0.4516$ & Confirmed \\
7 & Performance measurement & Improving quality & 12.258 & 0.000 & 209 & $0.3746-0.5182$ & Confirmed \\
\hline
\end{tabular}

As we can observe from the results of Table 1, the seven null hypotheses have been rejected, which means organizational support along with developing programs could influence the quality of organization. According to our survey, using e-learning to learn more must be considered in medical schools and there must be some supportive programs to help students learn on how to use the elearning systems. The same supportive people and equipments are also required for instructors to help them $\log$ in to the systems and use better features of the proposed models. Another advantage of using e-learning systems is the capability of giving sophisticated exams through internet where many 
people from different locations could attend such exams and by providing their identity they could use these facilities for continuous improvement of their skills.

\section{Conclusion}

In this paper, we have introduced information technology as an important event in new century. The information technology has changed the ways people learn and communicate. People could go through internet to have an access to many knowledge based websites such as Wikipedia to learn or they may take part in e-learning programs offered by different well known universities in the world without bothering about the borders between countries. We have also explained that e-learning has proven as a cost efficient method especially for courses where there is no need to offer physical lab courses. It can literally eliminate different cost involved with traditional learning such as transportation or the cost of leaving a job to learn more. The proposed study of this paper tried to understand whether e-learning had any positive impact on quality improvement in an organization. The proposed study of this paper performed a survey on 525 people who worked in medical school of Ilam. We have chosen a sample of 223 people and designed a questionnaire based on Likert scale. The results indicate that e-learning has positive relationship with quality improvement in an organization. Based on the results of our survey, using e-learning to learn more must be considered in medical schools and there must be some supportive programs to help students learn on how to use the e-learning systems. The same supportive people and equipments are also required for instructors to help them log in to the systems and use better features of the proposed models.

\section{Acknowledgment}

The authors would like to thank the anonymous referees for their constructive comments on earlier version of this work.

\section{References}

Abdelaziz, M., Samer Kamel, S., Karam, O., \& Abdelrahman, A. (2011). Evaluation of E-learning program versus traditional lecture instruction for undergraduate nursing students in a faculty of nursing. Teaching and Learning in Nursing, 6(2), 50-58.

AbuSneineh, W., \& Zairi, M. (2010). An Evaluation Framework for E-Learning Effectiveness in the Arab World. International Encyclopedia of Education, $3^{\text {rd }}$ ed., 521-535.

Bhuasiri, W., Xaymoungkhoun, O., Zo, H., Jeung Rho, J., \& Ciganek, A.P. (2012). Critical success factors for e-learning in developing countries: A comparative analysis between ICT experts and faculty. Computers \& Education, 58(2), 843-855.

Cegarra-Navarro, J.G., Jiménez Jiménez, D., Ángel Martínez-Conesa, E. (2007). Implementing ebusiness through organizational learning: An empirical investigation in SMEs. International Journal of Information Management, 27(3), 173-186.

Cronbach, L. J. (1951). Coefficient alpha and the internal structure of tests. Psychometrika, 16(3), 297-334.

Ćukušić, M., Alfirević, N., Granić, A., \& Garača, Ž. (2010). e-Learning process management and the e-learning performance: Results of a European empirical study. Computers \& Education, 55(2), 554-565.

Keramati, A., Afshari-Mofrad, M., \& Kamrani, A. (2011).The role of readiness factors in E-learning outcomes: An empirical study. Computers \& Education, 57(3), 1919-1929.

Krause, U.M., Stark, R., \& Mandl, H. (2009). The effects of cooperative learning and feedback on elearning in statistics. Learning and Instruction,19(2), 158-170. 
Likert, R. (1932). A Technique for the Measurement of Attitudes. Archives of Psychology, 140, 155.

Payne, A.M., Stephenson, J.E., Morris, W.B., Tempest, H.G., Mileham, A., \& Griffin, D.K. (2009).The use of an e-learning constructivist solution in workplace learning. International Journal of Industrial Ergonomics, 39(3), 548-553. 